writing-namely, its inclination to excess and the compulsory nature of the practice-are precisely what royalist poets praise. For these writers, health drinking presents an opportunity to submit oneself wholly to a community construed both congenially and politically.

The book's conceptual contributions to the field, as well as the analytical contributions of its chapters on Shakespeare and health drinking, outweigh dramatically its few inconsistencies. Its chapter on Faustus offers an ingenious reading of the play, but one the book does not substantiate fully. Missing here is a more developed account of the status of the will in Reformed discourses of repentance. Additionally, it would have been helpful for the book to articulate in greater detail its understanding of the conceptual significance of a contemporary (that is, a twenty-first-century) re-evaluation of addiction as a category of behaviour that might, as it did in the early modern period, generate positive as well as negative connotations; both the Introduction and the Epilogue seem to be making this suggestion. If, as Lemon indicates, one important aspect of addiction is that it describes a "shared process of being in relation" (167), is it not the case that contemporary cultures possess adequate resources with which to characterize this process or the resulting forms of relation without turning to the notion of addiction? Perhaps we do not, but the book does not take up this discussion directly. Regardless, as a literary and cultural study, Addiction and Devotion performs valuable scholarly work by recovering a lost history of addiction, and illuminating a wide range of cultural attitudes both towards specific addictive practices and towards different forms of addiction as determined by the relationship of the addict to their object.

DAN BREEN

Ithaca College

\title{
Parker, Patricia.
}

Shakespearean Intersections: Language, Contexts, Critical Keywords.

Philadelphia: University of Pennsylvania Press, 2018. Pp. $409+12$ ill. ISBN 978-0-8122-4974-3 (hardcover) US $\$ 59.95$.

Patricia Parker's Shakespearean Intersections epitomizes what its author does best: extracting potent lexical essences from the lowest-hanging to the 
farthest-fetched philological fruits by applying pressure to conspicuously plump textual words and phrases harvested from the plays of Shakespeare and his contemporaries; deriving a complex elixir from the historically and contextually nuanced distillations of those critical keywords, which often open startlingly clear interpretive vistas onto dramatic passages that have long eluded editors, scholars, students, and audiences of the plays; all the while collegially building upon and extending recent critical work, particularly in the fields of early modern gender and queer studies. Providing a rather prolific response to the age-old question, “what's in a name?" this book's methodological approach to words (including nominal) as uniquely rewarding vehicles for exploring the language, contexts, and preoccupations of a period's literature and dramatogether with oft-overlooked issues and historical intersections-testifies to the rich dividends paid by the meticulously close scholarly readings at which Parker is so adept.

Aptly beginning with a discussion of the cultural semantics of preposterous (or bottom-first) reversals, Parker highlights the frequent early modern analogy between writing and sexual practices that equated composing, spelling, or reading backward (including scripturally and arithmetically) with sodomy (or preposterous venery), but also with various kinds of inversions of the putatively-natural order (generational, patriarchal, social, racial, religious, and so forth). Applying these lexical and historical intersections to various allusions to preposterous reversal in Shakespeare's Love's Labor's Lost, Parker proceeds to elucidate how what might initially seem to be the disparate or unconnected spheres of reading, writing, orthography, sodomy, scatology, and biblical teleology/typology become intertwined in the play's polemical scapegoating and abjection of religious and racial otherhood. Turning in her second chapter to Shakespeare's The Taming of the Shrew, Parker illustrates how the preposterous reversal staged in the sub-plot scenes of Bianca's wooing by masters of competing arts serves as a marker of much broader invocations and inversions of order at work in the play as a whole, from the microlevel of rhetorical reversals to the broader disruptions and subversions of hierarchy, including the cambio or exchange whereby Bianca masters her masters (emerging by the play's post-marital conclusion as anything but a tamed wife), and the various inversions of status enabled by the play's dramatic and metadramatic cross-dressings and disguises (the "sub-positions" or "suppositions" already present in Ariosto's I Suppositi and Gascoigne's Supposes, the source 
texts for Shakespeare's Shrew). Preposterous constructions in the play, Parker concludes, repeatedly escape the binary logic of figuring in a single register, shifting instead between multiple meanings and contexts, such as gender, class, sexual position, and (meta-theatrical) transvestism.

In the book's third chapter, Parker casts her interpretive gaze upon the multilingual meanings of quinces in A Midsummer Night's Dream, widening her interpretive scope to include crucial visual contexts. While editors frequently align the surname of Peter Quince with carpentry coigns or quoigns (wedgeshaped blocks used at the corners of walls and houses for building purposes), rarely do they ever mention the importance of quince fruit in relation to the play's thematic concerns-an oversight that Parker's chapter fruitfully corrects. Noting the period's (and Shakespeare's) frequent exploitation of the sexual suggestiveness of the medlar and other types of fruit, and tracing the quince's connections to aphrodisiacs and love potions specifically intended to overcome female resistance to marriage, Parker amply demonstrates here (as she also does in her discussions of Cambio in chapter 2 and Brabantio in chapter 5) how Shakespearean names often introduce a complex connotative network that resonates within the world of the text and also with its contemporary historical contexts. Suggestive in relation to the love potion that enables both human and fairy couplings in A Midsummer Night's Dream, but also in relation to the comedy's representations of marriage, sexuality, unruly women, and female speech, is a nexus of contemporary associations for the overdetermined quince, from herbals linking it to pregnancy and fortunate progeny, to emblems associating it with Athenian weddings, marital concord, and sweetened bridal breath/speech. Combining these aforementioned connotations with the word's metamorphic spellings, multilingual valences, and homophonic network, Parker returns to carpenters' quoyns or corners, monetary coins and coining, and multilingual "con" words, like conjugio (marriage, matrimony, wedlock, copulation) and conno (a woman's private parts, or quaint), ultimately in order to ponder the play's preposterous pairings in relation to the quince's queer potential to cross or elide the hetero/homo divide. The book's fourth chapter considers preposterous inversion from yet another perspective by interrogating the ramifications of Shakespeare's producing the histories of Henry IV and $\mathrm{V}$ after having already presented the histories of Henry VI, thereby staging a preposterous, dramatic reversal of putatively-natural chronological, historical, and patrilineal order. Although Shakespeare's Henry V concludes with a choric 
Epilogue invoking the rhetoric of lineal succession, it is a play that (Janus-like) looks both ways at once, and that rhetoric-which occurs at the height of Henry's triumph-is simultaneously countered by the audience's dramatically ironic knowledge that the theatrical context of these dramatic histories reverses lineal sequence: the story of the son who would succeed his father (and lose all that his father had gained) had already appeared on the Shakespearean stage. Exposing in advance, then, what is suppressed, silenced, or left unsaid in Henry $V$ itself, the earlier plays' dramatizations of the aftermath of Harfleur result in Henry's emerging from his own history as an ambivalent or doubled figure haunted by a chronological future that is always already (preposterously) the dramatic past.

Musing over the name Brabantio, Desdemona's father in Shakespeare's Othello, Parker spends the book's fifth chapter exploring the capacious series of associations that its evocation of Brabant-a centre of Spanish power in the Low Countries with considerable financial and military significances-would have summoned in a global context for contemporary audiences of Shakespeare's play. Ultimately, Parker's ruminations on Antwerp's Burse in relation to both London's Royal Exchange and Iago's persistent invocations of "purse" in the play; references to Cassio as "cashier'd," a term brought back to England from the campaigns in the Low Countries; Brabant's identification with finance and accounting in relation to both Cassio's being an arithmetician and the play's morally and erotically charged rhetoric of credit and debt; the implication of Brabant in the 1588 Spanish Armada threat recalled in the threatened Turkish invasion of Cyprus in Othello; and cloth's associations with the Low Countries being bound up with the notion of female sexual honesty, particularly in relation to depictions of Desdemona's handkerchief-a textile overdetermined as a signifier of wealth, exchange, credit, reputation, sexual purity, and erotic work-all contribute to the play's wider global contexts and the imaginative resonances invoked by Shakespearean names. In the concluding chapter, Parker hunts for intimations of Ganymede in Shakespeare's late romance Cymbeline, citing approaches to the play that locate the link between King James and the Roman emperor Augustus (in whose reign the story is supposedly set) in the character of Jupiter, who descends on his eagle in act 5, thereby implicitly recalling the rape and promotion of the beautiful Trojan boy Ganymede in Hebe's (Juno's daughter's) stead as divine cupbearer. Reading this image in relation to the promotion of Jacobean Gentlemen of the Bedchamber and notorious 
favourites like James Hay and Robert Carr, Parker insists on the importance of the play's multiple references to preposterous venery, including the vaginally/ anally coded rings that here (as in so many other transvestite plays) serve as conspicuous vehicles for crossing the hetro/homo divide-though Parker is less forthcoming about how this reading illuminates the play's larger thematic concerns than about how it enables her to pull together the various threads of the book's chapter discussions.

While Parker's consistently impressive close-reading skills (reminiscent of epic simile in their occasionally threatening to overwhelm tenor via vehicular proliferation) are on full display throughout, the book's early discussion of preposterous reversals in various registers makes the most lasting impression. Fascinating as her chapter on the global implications of Brabantio's name in Othello is, its lack of a focus on preposterous inversion suggests that Parker has suddenly lost the plot, despite her labouring to illuminate the chapter's lexical intersections and the preposterous sodomitical implications posed by the threat of turning Turk. While the book might have been strengthened by editing for the preposterous reversals at its core, Shakespearean Intersections is a potent reminder not only of Parker's impressive interpretive skills but also of the efficacy of her methodologically braiding together via dramatic discourse seemingly disparate strands of early modern English culture to trace a network of interpretive association whose complex intricacies possess the reverberative power to amaze.

MARK ALBERT JOHNSTON

University of Windsor

\section{Pizan, Christine de.}

\section{The Book of the Mutability of Fortune. Ed. and trans. Geri L. Smith.}

The Other Voice in Early Modern Europe : The Toronto Series 52, Medieval and Renaissance Texts and Studies 514. Toronto : Iter Press ; Tempe : Arizona Center for Medieval and Renaissance Studies, 2017. xvi, 294 p. ISBN 978-086698-570-3 (broché) 44.95 US\$.

C'est un cadeau que nous fait Geri Smith avec une traduction allégée en anglais du Livre de mutacion de Fortune de Christine de Pizan. Cette première 